This item was submitted to Loughborough's Research Repository by the author.

Items in Figshare are protected by copyright, with all rights reserved, unless otherwise indicated.

\title{
Paradox and legitimacy in construction: how CSR reports restrict CSR practice
}

PLEASE CITE THE PUBLISHED VERSION

https://doi.org/10.1108/IJBPA-05-2018-0037

\section{PUBLISHER}

(C) Emerald Publishing Limited

\section{VERSION}

AM (Accepted Manuscript)

\section{PUBLISHER STATEMENT}

This work is made available according to the conditions of the Creative Commons Attribution-NonCommercialNoDerivatives 4.0 International (CC BY-NC-ND 4.0) licence. Full details of this licence are available at: https://creativecommons.org/licenses/by-nc-nd/4.0/

\section{LICENCE}

CC BY-NC-ND 4.0

\section{REPOSITORY RECORD}

Watts, Greg, Scott Fernie, and Andrew R.J. Dainty. 2019. "Paradox and Legitimacy in Construction: How CSR Reports Restrict CSR Practice”. figshare. https://hdl.handle.net/2134/35687. 


\title{
Paradox and legitimacy in construction: How CSR reports restrict CSR practice
}

\begin{abstract}
Purpose - Corporate Social Responsibility (CSR) is a prominent topic of debate, and yet remains subject to multiple interpretations. Despite this ambiguity, organisations need to communicate their CSR activity effectively in order to meet varied stakeholder demands, increase financial performance and in order to achieve legitimacy in the eyes of clients and various stakeholders. The purpose of this paper is to explore how CSR is communicated, and the impact such communication methods have on CSR practice. More specifically, it examines the disconnect between the rhetoric espoused in CSR reports and the actualities of the ways in which CSR is practiced.
\end{abstract}

Design - A qualitative content analysis of 100 CSR reports published by nine construction contractors informed the design of qualitative interviews. Seventeen interviews were then conducted with contractors and public body clients.

Findings - Strategic Ambiguity explains how contractors circumvent the problem of attending to conflicting stakeholder CSR needs. However, this results in a paradox where CSR is simultaneously sustained as a corporate metric and driver, whilst being simultaneously undermined in being seen as a rhetorical device. By examining this phenomenon through the lens of legitimacy, the study reveals how both the paradox and subsequent actions of clients that this provokes, act to restrict the development of CSR practice.

Originality - This is the first study to use the lens of legitimacy theory to analyse the relationship between CSR reporting and CSR practice in the construction industry. In revealing the CSR paradox and its ramifications the research provides a novel explanation of the lack of common understandings and manifestations of CSR within the construction sector.

Keywords: Social Value. CSR Reporting. Strategic Ambiguity. Paradox. CSR practice. 


\section{Introduction}

Broadly speaking, Corporate Social Responsibility (CSR) is argued to relate to an organisation's responsibility to contribute to society, but this responsibility is not enshrined as a specific legal obligation (Carroll and Shabana, 2010). Despite this, CSR debates and discussions have continued to grow in importance within the academic and industry literature. Partially driven by demands from clients, especially those in the public sector, CSR appears to have a function in legitimising an organisation's operations (Loosemore and Higgon, 2016) with CSR now considered by some as a social mandate (Lichtenstein et al., 2013). Strangely, there remains little agreement on what specifically constitutes CSR or what clearly differentiates and demarcates CSR practices from other organisational responsibilities (Carroll, 2015). It appears reporting on the use of CSR practices to legitimise an organisation's contribution to society is open to interpretation.

Formal reporting mechanisms depicting levels of engagement in CSR such as annual reports are arguably, problematic for organisations to craft, for stakeholders to interpret, and are potentially inconsistent from one organisation to another (Bachmann and Ingenhoff, 2016). As such, the motivation to communicate CSR practice and ensuring what is communicated has substance and resonates with the various stakeholders cannot be taken for granted. This is especially important to understand if, as the prevailing arguments claim, organisations seek legitimacy through the formal reporting of CSR to underpin their reputation, operational performance and financial results (Thorne et al., 2014).

Arguably, CSR reports serve multiple stakeholders. As such it is challenging to ensure what is communicated resonates with a wide audience (Hummel and Schlick, 2016). The discourse mobilised in such reporting may also be manipulated, with it argued that an organisation's self-reported performance may not reflect the practices undertaken (Font et al., 2012). It is questionable, therefore, whether the legitimacy sought or achieved actually reflects the CSR practices adopted. Indeed, it is not necessary to dig deep to reveal high profile examples of some of the largest organisations in the sector being exposed for a disconnect between the actual practices they adopt and their espoused CSR. Evidence of this includes where large contractors have vastly extended their supply chain's payment terms and used blacklisting in employment selection at the same time as promoting themselves as having good business practices (Knutt, 2018). There can, and clearly is, opportunities for disconnect between what organisations strategically communicate to the market to attain legitimacy and their operational practices. 
Careful communication and the use of discourse to persuade and convince may be just as important as CSR practice in realising the benefits CSR brings (Michelon et al., 2015). Indeed, developing skills and craft in communicating to stakeholders for the purposes of solely attaining legitimacy may actually be a more effective and efficient use of resource than investing in substantive and innovative CSR practices. The argument that it may be unacceptable to not engage in CSR because doing so is an industry norm (Loosemore and Lim, 2017) is tempered here with an argument that it may actually be 'unacceptable not to be perceived as engaging with CSR' that is the industry norm (Belal and Owen, 2015). Furthermore, if the CSR communicated does not reflect CSR practice it could be problematic as it may act to reinforce the ongoing use of ineffective or purely symbolic CSR practices. The aim of the research is thus to explore and explain how organisations within the construction industry develop, communicate and legitimise CSR practices, and to examine what the implications of this are to the development and evolution of CSR within the sector. The objectives are to establish how and why CSR is communicated, investigate examples of legitimacy theory use in CSR communication literature, and discover how such communications resonate with stakeholders. 


\section{CSR in Construction}

Despite its size and importance to the UK economy, construction has a poor public image (Farmer, 2016). Attempts to address this is agreed to be a motivating factor in contractors embracing CSR (Barthorpe, 2010). With notable CSR practice including charitable contributions, training communities and promoting environmental awareness (Lichtenstein et al., 2013). In addition to practices by contractors in response to image concerns, pressures on public spending have also led to questions on how greater value can be extracted from industry through public sector procurement, a more for less debate (Loosemore and Higgon, 2016). Consequently, changes in procurement criteria driven by the Public Services (Social Value) Act (2012) have formalised the need for public sector procurement to address additional social value, not just the traditional 'value for money' criteria (Loosemore and Higgon, 2016).

More than $25 \%$ of construction output is from the public sector therefore achieving social value is beginning to be widely scrutinised across numerous areas of practice. For example, its ability to: influence woman's participation in the sector (Wright, 2015); underpin wide-scale societal change (Barnard, 2016) and affect tendering practices for public sector work (Hoejmose and Adrien-Kirby, 2012). Of course, for the cynic, the social value agenda may also be viewed as a creative way for Government to leverage, from industry, solutions to plug the holes left by successive spending cuts in social services. Notably though, ideas of Government influencing organisational impacts on society are not new (see Carroll, 2008) and as such, social value is an extension of an ongoing historical trend towards developing more socially responsible organisations.

Rarely, if ever, has it been assumed that organisational interests naturally align with those of society (Jones et al. 2006). Indeed, prior to the development of the Social Value Act, many other important pieces of legislation including the Bribery Act (2010) and the Health and Safety at Work Act (1974) demonstrate Government attempts to influence the behaviour of organisations (Hughes et al., 2015). Such legislation is, however, limited to Government's ability to foresee the impacts of organisational decisions and the prevailing social norms. In more contemporary settings this acquiescence to social goals, for those seeking to win public sector work, has now been extended to include a need for organisations to evidence their social value.

Undoubtedly, it has now become an expectation of all stakeholders that construction organisations take responsibility for the impact their operations have upon the social and natural environment (Loosemore and Higgon, 2016). As a method of encouraging and enforcing contractor CSR behaviour public bodies have on the back of the Social Value 
Act, introduced additional procurement criteria to measure CSR (Watson et al., 2016). Indeed, CSR is now considered as being equally important to that of time, cost and quality in the procurement of public construction projects (Loosemore and Higgon, 2016). However, despite this, there is still no widely agreed consensus on what constitutes legitimate CSR practice. The Social Value Act itself fails to provide clarity on specific practices instead accepting that the various interpretations of social value can result in inconsistent practice and act as a barrier to its ongoing implementation (Young, 2015). It is however, clear that despite any varying interpretations CSR must be communicated effectively between stakeholders for procurement benefits to be realised. Yet it remains unclear exactly how CSR is reported, and the impact such reporting has upon CSR practice.

\section{CSR Communication}

CSR reports are an increasingly popular method for organisations to communicate CSR (KPMG, 2017) and are usually either issued annually as standalone documents or integrated with financial reports (Thorne et al., 2014). Research on CSR communication has tended to be largely quantitative using questionnaires (see Bachmann and Ingenhoff, 2016; Thorne et al., 2014) or consisted of a review of the CSR reports themselves (see Font et al., 2012; Michelon et al., 2015). Whilst such results can elucidate interesting findings, they arguably lack a deeper insight into the motivations and interpretations of key actors. One contemporary debate within CSR reporting is whether organisations substantially (meaningful engagement with CSR principles) or symbolically (greenwash) engage with CSR (Michelon et al., 2015). Evidence of symbolic engagement has however been found to be significant within many contemporary CSR reports (Michelon et al., 2015). For most stakeholders however, differentiating between symbolic or substantive CSR is largely down to interpretation of CSR communication. Indeed, at best CSR reports appear to be designed to communicate only what organisations want stakeholders to perceive.

Such a jaundiced view does not, however, necessarily reveal the full complexity of CSR communication as CSR reports communicate to multiple stakeholders each with particular interpretations of what constitutes CSR. Although, how CSR is communicated via a single report and understood by disparate stakeholders is often overlooked. Understanding this can be facilitated by mobilising the lens of Strategic Ambiguity (SA) to identify and explain the use of ambiguous language as a way to simultaneously connect with disparate stakeholders. SA allows contradictory interpretations to coexist 
but, at the same time, satisfy diverse and disparate stakeholder interests through a single piece of information (Eisenberg 1984). Indeed, previous work has found evidence of ambiguous language use when communicating social, environmental and financial information that served to develop shared understandings between the organisation and its stakeholders (Wexler, 2009). For organisations, communicating via ambiguous language helps them to: 1) allow and promote diverse opinions, 2) provide an overview without detail, 3) use flexible and vague concepts, and 4) allow changes to occur easily (Fernando and Sim, 2011).

Attempting to establish what is or is not CSR practice, let alone what is successful and why, is therefore problematic if reliance is placed on exploring CSR reports alone. That is not to denigrate the existing studies that have used reports, but to highlight the idea that reports alone provide a limited understanding of organisational CSR. Indeed, reports may give the wrong impression of an organisation's CSR. This matters for the development of CSR both practically and theoretically as reports can inadvertently act to reinforce poor practice and hide poor CSR performance.

\section{CSR and Legitimacy Theory}

The debates around defining CSR are varied, numerous and ongoing (Carroll, 2015). Such variations undoubtedly provide considerable flexibility and support for the existence of numerous CSR interpretations. This flexibility may then of course create confusion and tensions where interpretations and definitions clash, or are in competition, and contradict with one another (Carroll, 2015). Research has attempted to embrace this flexibility by discussing CSR as concept specific to individual organisations (van Marrewijk, 2003) and also CSR as a broad concept relevant to a wider constituency such as industries (Barthorpe, 2010). Whilst this flexibility is useful for encouraging an extensive spectrum of research and practice in the field of CSR, it does create problems in determining what constitutes CSR and indeed, ongoing developments in this nascent field of theory and practice.

Regardless of consensus or flexibility, CSR has undoubtedly grown to become an important feature of contemporary organisational practice with a body of literature dedicated to exploring CSR. Recent debates in the literature have begun to distinguish CSR practice from the oft argued philanthropy of wealthy businessmen to something that more carefully connects societal expectations and the need for organisations to make an impact on society through CSR practices (Murray and Dainty, 2009). Incentivising 
organisations to mobilise novel and innovative CSR practices is an argument that organisations should benefit from CSR via increased financial performance, reputation and customer satisfaction (Saeidi et al., 2015). Arguably, what really matters is that society and clients perceive organisational practices to serve their interests. Through achieving this, organisations are then legitimately perceived (Thorne et al., 2014) to conform, for example, to expected behaviours, legal requirements and to the fair treatment of stakeholders (Bachmann and Ingenhoff, 2016). The perception provided by organisations that they engage in substantive CSR practices is thus fundamental to understanding how organisations achieve legitimacy and arguably central to understanding future developments in CSR practice.

Legitimacy theory has previously been used to provide an explanatory insight into the decisions of organisational actors motivated by legitimacy seeking behaviour (Suchman, 1995). According to O'Dwyer et al., (2011, p34) "legitimation processes aim to justify both the work professions undertake (are the results produced culturally valued?) and how it is undertaken (are the results produced in a culturally approved manner?)". The theory is used in several studies to better understand different facets of CSR and provides a lens to evaluate organisational decisions in their attempts to gain and maintain legitimacy in the eyes of stakeholders (Duff, 2017). It is argued by Suchman (1995) that there exists three different broad forms of legitimacy; pragmatic, moral and cognitive.

\section{Pragmatic Legitimacy}

This focusses on the practical consequences that arise from exchanges between organisations and stakeholders (Suchman, 1995). It is further broken down into three sub categories of legitimacy where: the organisation develops practices they believe will lead to legitimacy (exchange legitimacy); stakeholders believe organisations are acting for wider interests (influence legitimacy), and; the organisation is perceived by stakeholders as having an image associated with genuine societal concern (dispositional legitimacy). It is clear that all three forms of pragmatic legitimacy involve beliefs and perception and as such are susceptible to manipulation, with it argued that there is a 'durability pendulum' with pragmatic legitimacy being 'the easiest to obtain but the least durable' (O'Dwyer et al., 2011, p.34).

\section{Moral Legitimacy}

This is achieved where the stakeholder(s) perceive an organisation to be fundamentally doing the right thing (Suchman, 1995). Its sub categories are where: organisations are 
judged on what they achieve (consequential legitimacy); where socially accepted techniques and practices are adhered to (procedural legitimacy); if its resources can achieve its goals (structural legitimacy) and; evaluations are made about those in charge of the organisation (personal legitimacy) (Duff, 2017). According to Reast et al., (2013) moral legitimacy is often sought from sceptical stakeholder groups who morally object to an organisation's operations.

\section{Cognitive Legitimacy}

This is when stakeholders believe an organisation's motivations mirror their own (Duff, 2017). Cognitive Legitimacy comprises of comprehensibility, where the organisation structures itself in an understandable way to intended stakeholders, and taken-forgranted, which refers to when stakeholders view the organisation as one of the only available to deliver the service they need (Suchman, 1995). Cognitive legitimacy is argued to be the hardest to achieve yet the most durable (Belal and Owen, 2015) arguably because it operates at a subconscious level and so requires longer-term deeper rooted practices to influence (O'Dwyer et al., 2011).

The three types of legitimacy are not mutually exclusive however, and in practice can merge, reinforce, or even come into conflict with one another. Organisations can attempt to progress along the continuum of legitimacy from pragmatic to cognitive or can simply attempt to gain different types of legitimacy from different stakeholder groups (Belal and Owen, 2015). There is also an increasing body of literature considering the types of legitimacy techniques employed by organisations with 'symbolic legitimation' referring to organisations demonstrating social expectations in an effort to gain legitimacy without changing their practices (Belal and Owen, 2015). 'Substantive legitimation' is when organisational practices are fundamentally altered in an effort to attain legitimacy, although in both cases the results would need to be communicated to stakeholders for any benefits to be achieved (Belal and Owen, 2015). Some previous studies which have utilised legitimacy theory to explain CSR have failed to explore the nuanced forms of legitimacy (see Thorne et al., 2014). However, one study that considers how the categories of legitimacy influence organisational behaviour was that conducted by Duff (2017) who found evidence of organisations successfully maintaining legitimacy through the use of CSR. Although Duff (2017) fails to explore the organisational ramifications of maintaining such legitimacy. Whilst it is clear that organisations use CSR reports to legitimise their operations, it is unclear whether this is based on symbolical or substantive practices, and equally unclear how once achieved, such legitimacy then impacts upon future CSR reporting and practice. 


\section{Research Design}

This research seeks to explore how CSR is communicated, and how understandings and interpretations of such communication impact CSR practice. Therefore, the data collection naturally falls into two categories. The first, an analysis of CSR reports that extends beyond the oft used quantitative analysis, which will then serve to inform the second; interviews conducted with key stakeholders. An interpretivist methodology is therefore adopted as it provides for a deep understanding of how a concept is interpreted and understood (Cresswell, 2013). It is argued that an interpretivist standpoint allows for a detailed understanding as its focus is individual experiences, the understanding of which help illustrate the socially constructed phenomena under investigation (Ozuem et al., 2014). This study adopts the position that CSR is such a social construct, as its meaning is subjectively agreed between different stakeholders (Erdiaw-Kwasie, 2014).

\section{Qualitative Content Analysis}

In the first instance UK based contractors were ranked by turnover in the year 2016 . From those contractors who populated the top 20 positions and operated in the public sector one was selected at a time and all CSR reports downloaded between the years 2005 and 2017. This procedure was then repeated and another contractor selected until 100 CSR reports were downloaded. This resulted in all available CSR reports for nine contractors being reviewed. As CSR Reports are known by a variety of names, documents were included if they met three criteria adopted from Thorne et al., (2014) in that they 1) were distinctly different from the organisation's annual report, 2) contained content is over and above what is considered mandatory, and 3) focussed upon social and environmental topics.

The QCA was human led but exploited software for the counting of words (Lock and Seele, 2016) which consisted of using a desktop PDF based word finder. Each report was searched for a total of 179 different key words derived from the literature and the CSR reports themselves. The frequency each key word occurred was recorded in a coding manual, a document that contains the categories of content (i.e. key words) recorded under various dimensions (i.e. the number of occurrences) (Bryman, 2016). The context around each key word use was then reviewed and recorded adding both texture and background (Bennett, 2015). The coding manual then became a coding schedule, a document where all data associated with the key terms is recorded (Bryman, 2016). The coding schedule now allowed an analysis and comparison of both key word frequency and context to occur. 


\section{Semi-Structured Interviews}

The results of the coding schedule informed semi-structured interviews. Ten different potential interviewees were contacted from contractors and ten from public bodies with interviews conducted with those who responded positively. In total interviews were conducted with eight public sector clients and nine UK contractors. Such interviews allowed the desired areas of interest to be pursued, yet retained the freedom and flexibility to explore unexpected trails of information (Bryman, 2016). Conducting the interviews via telephone allowed qualitative data to be gained whilst simultaneously empowering participants to respond from a comfortable setting (Cresswell, 2013). The websites of the contractors whose CSR reports were analysed were reviewed with email introductions sent to individuals purposefully selected as most appropriate to deliver applicable responses (Bryman, 2016) - those who had responsibility for strategizing, communicating and practicing CSR. A similar approach was adopted for interview participants from public sector clients with websites reviewed and interview requests sent via email to applicable individuals, such as those with construction procurement responsibilities. Figure 1.0 shows the interview sample.

[INSERT FIGURE 1.0 'interview sample' HERE]

\section{Analysis of Interview Data}

A framework for analysis was created based on the sub-categories of legitimacy proposed by Suchman (1995). It consisted of a table with each sub-category listed in a column on the left hand side. The results of the interviews were then coded with qualitative codes, this is where a uniform set of indexing categories are systematically applied to the data sets (Mason and Simmons, 2011). The qualitative codes were the sub-categories of legitimacy. Each coded response was then input against the corresponding legitimacy sub-category on the framework. Such a qualitative analysis allowed an interpretation of the data identifying larger themes, deeper meanings, and individual motivations (Creswell, 2013) as well as revealing the type of legitimacy sought/afforded by each interviewee. 


\section{Findings and Discussion}

The size and terminology of CSR reports and contractor motivations for reporting

Analysis of the QCA revealed that CSR reports are reducing in size. In 2012 the average number of pages per CSR report was 33, falling to 27.5 in 2013 and 17.8 in 2014. The QCA exposed the somewhat compact style of writing each report contained, for example in 2013 one contractor simply stated "140 placements through business action on homelessness" as their total contribution towards describing the issue. When the size and content of CSR reports was raised with contractors', one commented:

"...we try and give a balanced view of all our activities...some do get missed out and we can't always give as much detail as we'd like...but we need our report to show as much as possible because we have lots of people reading it" (CC2).

However, despite this reduction in length of CSR reports, the terminology used in each report remains constant, with the QCA revealing the same words used year upon year, irrespective of contractor or year of publication, as can be seen in figure 2.0.

[INSERT FIGURE 2.0 'Qualitative Content Analysis Results' HERE]

When such findings were discussed in the interviews one contractor commented that:

"We've won lots of work over the last few years which has been as a result of our approach to CSR...and how we've reported it...so we're not about to change what we do" (CC1).

With another stating a reluctance to change how they report on CSR in fear of being perceived as inferior to competitors and not meet stakeholder expectations. However, contractors' attempts to promote the best examples of their behaviour whilst ensuring reports remain increasingly succinct potentially results in increased pressure to meet varied client CSR expectations. Analysis of such findings through the lens of legitimacy theory revealed the consistent use of the same terminology closely aligns with aspects of the procedural and structural sub-categories of moral legitimacy. It was also revealed that contractor responses align with exchange and influence legitimacy, sub-categories of pragmatic legitimacy, as contractors are purposefully attempting to portray themselves as meeting stakeholder demands through reporting varied CSR practices. Arguably, contractors are therefore maintaining the reporting techniques they feel are socially approved in an effort to gain and maintain legitimacy. The findings therefore 
resonate with those in the literature that organisations are motivated to produce CSR reports as a method of appearing legitimate (Belal and Owen, 2015; Thorne et al., 2014). As this paper seeks to expand upon current gaps in literature contractors were then asked about their CSR reporting motivations. With contractors stating:

CSR reporting "...allows us to put our best selves forward..." (CC7).

"...it's partly an expectation we have to meet; clients want to see that we're a business that gives back" (CC1).

"...of course some of what we do is for clients, that's why we [communicate] our CSR... a lot of the time [our CSR] comes as a result of what clients want" (CC6)

And,

"...reporting [on CSR] is expected these days, we need to do it just to stay competitive...everyone is doing it so we need to think about what we can do more, that will really set us apart" (CC2).

When asked what content was reported contractors believed that:

"We report much more on the substantive issues, the things that really matter in society...if the report was just a greenwash I wouldn't work here" (CC4).

Analysis revealed that despite altruistic arguments by some contractors a large motivating factor in CSR reporting is that procedural legitimacy, a sub-category of moral legitimacy, is sought by contractors who want to abide by the perceived social expectations to report on CSR. The interviews also revealed that contractors are motivated to report on CSR to promote their own image as one of concern for society, closely aligning with dispositional legitimacy, a sub-category of pragmatic legitimacy. Contractors also all believed that they substantively report on CSR and therefore all desired substantive legitimation from clients.

Appearing legitimate it seems, is an underlying motivation for contractors to report on CSR. Despite the potential difficulties shorter CSR reports may have in successfully resonating with diverse stakeholders, contractors appear to persist in the production of shorter CSR reports and the use of the same terminology. This appears to be in an attempt to meet a perceived stakeholder expectation that producing CSR reports is a 
standard and expected behaviour, confirming arguments from the literature (Loosemore and Lim, 2017).

However, despite the motivations to report on CSR to be perceived as legitimate, arguably the reducing size of CSR reports and resulting compact style of writing could potentially serve to restrict the number of stakeholders who understand contractor CSR reports thereby reduce any legitimacy unless behaviours are adopted by contractors to circumvent such potential issues. 


\section{Contractors' use of ambiguous language}

The QCA revealed the word 'sustainability' is used in one 2014 CSR report to discuss environmental issues such as energy efficiency and procuring responsibly sourced materials and in another 2014 report to discuss local communities and social regeneration. This was not overly surprising given that terms such as CSR and sustainability mean different things to different contractors (Barthorpe, 2010). Although somewhat surprisingly, the QCA revealed that some terms actually mean different things to the same contractor. One example of this, again with the word 'sustainability', is that in 2008 one contractor used the term to describe their carbon footprint and ethical and profitable business growth. However, in 2012 the same contractor used the term to include wider environmental and societal issues, and in 2015 expanded the term further still to include wider business practices, energy efficiency, staff progression, supply chain upskilling and building strong stakeholder relationships.

It is here where the theoretical lens of SA can be mobilised to help explain how such ambiguous language attends to contractor needs in serving multiple stakeholders simultaneously with a single CSR report. The findings complement those of Fernando and Sim (2011) in that SA use appears to; 1) allow diverse opinions - in the form of different contractors using the same terms for different activities, 2) provide an overview without detail - the term 'sustainability' is used often but detailed descriptions of exact activities undertaken are not, 3) allow flexible and vague concepts - the activities the term 'sustainability' covers vary for each contractor, and 4) to allow changes to occur easily the activities one contractor provides under the term 'sustainability' change over time. When asked why ambiguous terms were used and what the intentions were behind such word choice, contractors' responses included:

"The terms we use are the ones people are familiar with... we need everyone to understand what we have done and what we are doing" (CC6).

And:

"We use the language people understand...everyone who reads our [CSR] report can understand what we're doing...as we work with [different] clients all over the country who all want different things...if we're too specific then half the people who read [the CSR report] won't be interested..." (CC9).

Analysis of such findings reveals that the results of both the QCA and interviews closely align with all three sub-categories of pragmatic legitimacy. Contractors' attempt to gain 
exchange legitimacy through using ambiguous language in an effort to ensure CSR reports simultaneously resonate with numerous stakeholders. Contractors also want to be perceived by stakeholders as sharing their concerns, and want their legitimacy to be judged on the production of such CSR reports, sharing characteristics with all moral legitimacy sub-categories, specifically consequential legitimacy.

The findings therefore reveal how the use of the same terminology by all contractors across all reporting years attends to the needs of different stakeholders. By using ambiguous language, contractors circumvent clearly defining what they believe CSR to be, adding a somewhat new insight to the long-standing problem in the literature that no widely agreed CSR definition exists amongst stakeholders (Carroll, 2015). The findings suggest this is intentional by clients so that, through ambiguous language use, they can reach agreed CSR definitions with individual clients. The use of SA allows flexibility to exist so contractors can assign meanings to suit their own communicative needs, which in turn allows contractors to be perceived as legitimate by numerous clients simultaneously. Therefore, contractors can be considered successful in their attempts to gain legitimacy though the use of ambiguous language when CSR reporting. Such findings reinforce arguments in the literature that CSR legitimises an organisation's operations in society (Loosemore and Higgon 2016). However, this research sought to build upon such findings and discover if it was CSR practice that gained such legitimation or simply the process of reporting on CSR. 
The wider implications of clients considering contractors as legitimate When asked how they perceive the contractors who produce CSR reports, one client responded:

"Reporting on CSR is expected...I can't think of one contractor we work with who doesn't" (PSC4).

Clients were also asked if the contractors they worked with substantively or symbolically reported on CSR, with all clients believing that all contractors substantively reported. No client however, could provide an example of a contractor symbolically reporting on CSR. This could potentially be due to all contractors substantively reporting, of the fact that clients are unable to distinguish between the two types of CSR report. The latter was perhaps revealed when the use of ambiguous language and reduction in size of CSR reports was raised, with clients commenting:

"We don't really have time to fully review a long document [CSR report]... contractors are getting better at telling us what we want to know" (PSC5).

And,

The size of the report and language used is irrelevant "...as long as we can both understand each other...and the contractor delivers what's agreed" (PSC3).

It also became apparent across all clients that simply by reporting on CSR contractors were considered legitimate, and viewed as if they had substantively rather than symbolically reported, as clients stated:

"...the very production of a CSR report confirms that the contractor is serious about delivering CSR and has the team to do it" (PSC1).

"Once I've seen [the CSR report]...I can tell pretty quickly if the company is for real..." (PSC3).

And,

"[Their] CSR report showed us everything they can do...so we know they can meet our requirements" (PSC7). 
In addition to clients believing contractors who produce CSR reports substantively engage with CSR, contractors are also considered morally legitimate as clients see reporting on CSR as evidence of positive leadership intentions (personal legitimacy) and that the contractor has the resources capable of delivering the CSR reported (structural legitimacy).

Contractors were also then judged on their reported practices as to whether or not they could meet future demands and how they generally operated within society, closely aligning with influence legitimacy. It was found that this occurred due to a client belief that what is contained within a CSR report was evidence of what that contractor can and will deliver, as one client observed:

"[CSR] reports usually contain case studies...these show us what contractors have done and we expect that can continue to do them in future for us...as well as anything else they offer" (PSC1).

Interestingly the interviews with clients also revealed that once a contractor is considered legitimate it is difficult for them to lose such a standing, even if undesirable practices are subsequently revealed, as one client commented:

"If there's a relationship in place then we know we can trust [the contractor] to deliver...sometimes we do hear about things they've done elsewhere which we're not happy with...but that rarely effects the relationship we have with them." (PSC2)

Such findings reveal that clients consider contractors as pragmatically and morally legitimate when they produce CSR reports. However, it appears, clients find it difficult to distinguish between contractors who symbolically and substantively report on CSR, and once contractors are perceived as legitimate, they retain such an image even if transgressions occur. This then exposed a potential drawback in the use of ambiguous language for both clients and contractors who substantively engage with CSR reporting. Contractors who only symbolically engage with CSR could masquerade as those who substantially engage. Thereby receive the same legitimacy benefits, simply by hiding behind ambiguous language use. Therefore, some contractors arguably have the choice to engage in and communicate their practices (driven from a social institutions agenda) via ambiguous language to receive legitimacy, or ambiguously communicate CSR that does not reflect their own poor practices (a neo classical agenda) yet still receive the same legitimacy. 
The use of ambiguous language also serves to create a paradox, a true yet contradictory statement that is both correct and impossible. This simultaneously sustains CSR (as a corporate metric and driver) and undermines it (in being viewed as a rhetorical device). In this instance the paradox both encourages and prevents the agreement of defining CSR between a contractor and single stakeholder. Being specific enough in their CSR descriptions to reach an agreement with a single client for example, would undoubtedly alienate other clients with different CSR interpretations. The development of CSR practice could therefore potentially be restricted, as to be considered legitimate contractors could simply symbolically engage with CSR (hiding behind ambiguous language) thereby saving resources compared to competitors who substantively engage. The same legitimacy benefits would be realised with either option however substantive engagement would arguably be much more resource intensive. Additionally contractors who do substantively report on CSR will potentially have any benefits reduced as the ambiguous language needed to ensure CSR reports are widely accepted and understood will obfuscate the benefits of substantive CSR practice. CSR reporting it appears, is arguably more important than actual CSR practice.

When the concept of cognitive legitimacy was raised, one client commented that:

"We'll have to work with a contractor for many years with lots of positive results... where they have really gone above and beyond on a regular basis...and continued to innovate with what they can deliver...in order to see them as a long term 'go to' partner" (PSC3).

However, no client could provide examples of advantages contractors perceived as cognitively legitimate had over ones only viewed as pragmatically and morally legitimate. Arguably, contractors could therefore have little motivation in attempting to be viewed as cognitively legitimate as they may gain no further benefit for the additional resources required.

Interestingly, using the lens of legitimacy theory as a framework to analyse the findings also revealed that contractors could maintain pragmatic and moral legitimacy by continuing to report on CSR. Therefore, any contractor transgressions or negative publicity in other areas would rarely lead to a loss in legitimacy. Potentially allowing contractor practices to occur that are not socially responsible (such as extending subcontractor payment terms or blacklisting employees) with little resulting negative impacts felt on current relationships. Such practices could ultimately continue unless clients are more robust and rigorous in their analysis of contractor CSR reports and consideration of legitimacy. Reserving cognitive legitimacy appears an ineffective 
method by which to motivate contractors to substantively engage with CSR as pragmatic and moral legitimacy are so freely awarded by clients and allow contractors to achieve their legitimacy goals. Therefore, without clients rethinking what they consider as legitimate behaviour, the future development of CSR practice is arguably restricted. 


\section{Conclusion and Recommendations}

CSR reporting is increasingly expected of contractors (KPMG, 2017) yet there is little agreement as to what specifically constitutes CSR (Carroll, 2015). Despite this CSR reports serve multiple stakeholders and therefore ensuring what is communicated resonates with each is arguably challenging (Hummel and Schlick, 2016). Nevertheless, it is argued in the literature that reporting on CSR affords contractors legitimacy in the eyes of stakeholders (Thorne et al., 2014). However, it is questionable whether the legitimacy sought or achieved reflects CSR practice or CSR discourse. Therefore, CSR communication may be just as important as CSR practice in realising the benefits CSR brings (Michelon et al., 2015). Contemporary arguments within the legitimacy of CSR reporting have also centred around whether an organisation does and/or is perceived to substantially or symbolically report on CSR, with evidence showing symbolic engagement to be high (Michelon et al., 2015). The perception provided by organisations that they engage in substantive CSR practices is thus fundamental to understanding how organisations achieve legitimacy and arguably central to understanding future developments in CSR practice. However, CSR reports may give the wrong impression of an organisation's CSR and therefore can inadvertently act to reinforce and hide poor CSR performance. In order to understand how CSR is reported and understood by disparate stakeholders, the lens of Strategic Ambiguity (SA) is mobilised which identifies and explains the use of ambiguous language in CSR reports.

A Qualitative Content Analysis (QCA) of 100 CSR reports from 9 of the largest UK construction contractors informed semi-structured interviews that were conducted with both contractors and public sector clients. The theoretical lens of legitimacy theory (Suchman, 1995) was applied to analyse the coded interview results. The findings revealed that ambiguous language is used in the reporting of CSR, as debates in the literature had predicted (Fernando and Sim, 2011) and also that the publication of CSR reports was driven by legitimacy motivations (Belal and Owen, 2015). However, addressing a gap in current literature the paper found that SA was intentionally used to circumvent the problem of specific terms resonating with one stakeholder at the expense of another. Such techniques were successful at allowing contractors to be perceived as legitimate, with clients not only awarding both moral and pragmatic legitimacy to contractors who reported on CSR, but also considering them to substantially engage with CSR.

Perhaps most interestingly, it was revealed that using SA created a paradox as CSR was simultaneously sustained (as a corporate metric and driver) and undermined (in being 
viewed as a rhetorical device). This paradox both encouraged and prevented the precise defining of CSR, and combined with how freely clients consider those who report as legitimate, arguably permits contractors who only symbolically engage with CSR to masquerade as those who substantially engage. Contractors therefore have the choice to communicate their practices (driven from a social institutions agenda) via ambiguous language and receive legitimacy or communicate CSR that does not reflect their practices (a neo classical agenda) yet receive the same legitimacy. Additionally, contractors who do substantively report on CSR will potentially have any benefits reduced as the ambiguous language needed to ensure CSR reports are widely accepted and understood will obfuscate the benefits of substantive CSR practice. It appears CSR reporting is more important than CSR practice at allowing contractors to be perceived as legitimate.

Legitimacy theory also revealed contractors could maintain pragmatic and moral legitimacy by continuing to report on CSR, allowing socially irresponsible practices to occur with little resulting negative impacts felt on current relationships. Such practices could ultimately continue unless clients are more robust and rigorous in their analysis of contractor CSR reports. Without clients rethinking what they consider as legitimate behaviour, the development of CSR practice is arguably restricted. It appears that in construction, rather than it being considered "simply unacceptable not to be engaging in CSR..." (Loosemore and Lim, 2017, p103) it is only unacceptable not to report on CSR, irrespective of symbolic or substantive practice.

The broader implications are potentially profound as the results indicate that contractors who only symbolically engage with CSR receive the same legitimacy benefits as those who substantively engage. Arguably, such legitimacy translates into successful procurement that therefore means contractors are winning work but failing to deliver the social value promised, resulting in areas of society that need such social value left deprived. Public sector clients need to be aware of contractors who mobilise CSR as purely rhetoric and therefore solely as a symbolic device. Such competitors could appear to be the most cost-effective but only as fewer resources are spent on CSR practice, thereby restricting the amount of social value achieved. The implications for research include providing an insight into a previously unexplored sphere within the concept of CSR reporting, as well as contributing to the understanding of the relationship between CSR reporting and CSR practice. 


\section{References}

Bachmann, P. and Ingenhoff, D. (2016). "Legitimacy through CSR disclosures? The advantage outweighs the disadvantages", Public Relations Review. Vol. 42, pp 386-394 Barnard, C. (2016). To boldly go: Social clauses in public procurement. Industrial Law Journal, 46(2), 208-244.

Barthorpe, S. (2010), "Implementing corporate social responsibility in the UK construction industry", Property Management, Vol. 28, No. 1, pp. 4-17.

Belal, A. and Owen, D. (2015). The rise and fall of stand-alone social reporting in a multinational subsidiary in Bangladesh: A case study. Accounting Auditing and Accountability Journal 27(8)

Bennett, A. (2015), "Found in Translation: Combining Discourse Analysis with Computer Assisted Content Analysis", Millennium: Journal of International Studies, Vol. 43, No. 1, pp 984-997.

Bryman, A. (2016), Social Research Methods, $5^{\text {th }}$ Ed. Oxford University Press, Oxford. Carroll, A. B. (2008). A history of corporate social responsibility: Concepts and practices. The Oxford handbook of corporate social responsibility, 19-46.

Carroll, A. (2015), "Corporate Social Responsibility: The centrepiece of competing and complementary frameworks", Organisational Dynamics, Vol. 44, pp. 87-96.

Carroll, A. and Shabana, K. (2010), "The business case for corporate social responsibility: a review of concepts, research, and practice", International Journal of Management Reviews, Vol. 12 No. 1, pp. 85-105.

Cresswell, J. (2013), Qualitative Inquiry and Research Design: Choosing Among Five Approaches. London. Sage Publications.

Duff, A. (2017), "Corporate social responsibility as a legitimacy maintenance strategy in the professional accountancy firm". The British Accounting Review, Article in Press, pp. 1-19

Eisenberg, E. (1984), "Ambiguity as strategy in organisational communications". Communication Monographs, Vol. 51, pp. 227-242

Erdiaw-Kwasie, M., Alam, K, and Shahiduzzaman, M. (2014). "Bettering corporate social responsibility through empowerment and effective engagement practices: An Australian mining perspective", In C Higgins, J Hendry and C VanSandt (eds), 2014 Proceedings of the International Association for Business and Society, 140-150.

Farmer, M. (2016). The Farmer review of the UK construction labour model: modernise or die. Time to decide the industry's future. Construction Leadership Council.

Fernando, M. and Sim, A. (2011). "Strategic ambiguity and leaders' responsibility beyond maximising profits". European Management Journal, Vol. 29, pp. 504-513 
Font, X., Walmsley, A., Cogotti, S., McCombes, L. and Hauser, N. (2012), "Corporate Social Responsibility: The disclosure-performance gap". Tourism Management, Vol. 33, pp. 1544-1553.

Hoejmose, S. and Adrien-Kirby, A. (2012). "Socially and environmentally responsible procurement: a literature review and future research agenda of managerial issue in the $21^{\text {st }}$ century", Journal of Purchasing and Supply Management, Vol. 18. No. 4, pp. 232242

Hughes, W., Champion, R. and Murdoch, J. (2015). Construction Contracts Law and Management, $5^{\text {th }}$ Ed. Routledge, Oxon.

Hummel, K. and Schlick, C. (2016). The relationship between sustainability performance and sustainability disclosure - reconciling voluntary disclosure theory and legitimacy theory. Journal of Accounting and Public Policy 35, 455-476.

Jones, P., Comfort, D., \& Hillier, D. (2006). Corporate social responsibility and the UK construction industry. Journal of Corporate Real Estate, 8(3), 134-150.

Knutt, E. (2018) Carillion liquidation leads to calls for fair treatment of workforce and supply chain. Health and Safety at Work. Accessed at:

https://www.healthandsafetyatwork.com/construction/carillion-liquidation-leads-callsfair-treatment-workforce-and-supply-chain. Accessed 24 July 2018 KPMG. (2017), "Current of Change". The KPMG Survey of Corporate Responsibility Reporting 2017, KPMG.

Lichtenstein, S., Badu, E., Owusu-Manu, D., Edwards, D, and Holt, G. (2013). Corporate social responsibility architecture and project alignments: A study of the Ghanaian construction industry, Journal of Engineering, Design and Technology, 11(3), 334-353. Lock, I. and Seele, P. (2016), "The credibility of CSR (corporate social responsibility) reports in Europe. Evidence from a quantitative content analysis in 11 countries", Journal of Cleaner Production, Vol. 122, pp. 186-200.

Loosemore, M. and Higgon D. (2016) Social Enterprise in the Construction Industry. Routledge, Oxon.

Loosemore, M., and Lim, B. T. H. (2017). Linking corporate social responsibility and organizational performance in the construction industry. Construction management and economics, 35(3), 90-105.

Mason, C. and Simmons, J. (2011). Forward looking or looking unaffordable? Utilising perspectives on corporate social responsibility to assess the factors influencing its adoption by business. Business Ethics: A European Review 20(2), 159-176 Michelon, G., Pilonato, S, and Ricceri, F. (2015), "CSR reporting practices and the quality of disclosure: An empirical analysis", Critical Perspectives on Accounting. Vol. 33, pp. 5978. 
Murray, M., and Dainty, A. (ed.) (2009), Corporate Social Responsibility in the Construction Industry. Taylor and Francis, London.

O'Dwyer, B., Owen, D., \& Unerman, J (2011). Seeking legitimacy for new assurance forms: The case of assurance on sustainability reporting. Accounting Organizations and Society 36(1), 31-52.

Ozuem, W., Howell, K, and Lancaster, G (2014). Corporate social responsibility: towards a context-specific perspective in developing countries. Social Responsibility Journal 10(3), 399-415.

Reast, J., Maon, F., Lindgreen, A., and Vanhamme, J. (2013). Legitimacy-seeking organisational strategies in controversial industries: a case study analysis and a bidimensional model. Journal of Business Ethics 118, 139-253

Rhodes, C. (2015), Construction Industry: statistics and policy. Nr 01432. House of Commons Library.

Saeidi, S., Sofian, S., Saeidi, P., Saeidi, S, and Saaeidi, S. (2015), "How does CSR contribute to firm financial performance? The mediating role of competitive advantage, reputation and customer satisfaction", Journal of Business Research. Vol. 68, pp. 341350

Suchman, M. (1995), "Managing Legitimacy: Strategic and Institutional Approaches", The Academy of Management Review. Vol. 20 No. 3, pp. 571-610

Thorne, L., Mahoney, L, and Manetti, G. (2014), "Motivations for Issuing standalone CSR reports: a survey of Canadian firms", Accounting, Auditing \& Accountability Journal. Vol. 27 No. 4, pp. 686-714.

van Marrewijk, M. (2003), "Concepts and Definitions of CSR and Corporate Sustainability: Between Agency and Communion", Journal of Business Ethics, Vol. 44 No. 2, pp. 95-105.

Watson, K. J., Evans, J., Karvonen, A., and Whitley, T. (2016). Capturing the social value of buildings: The promise of Social Return on Investment (SROI). Building and Environment, 103, 289-301.

Wexler, M. (2009). "Strategic ambiguity in emergent coalitions: the triple bottom line", Corporate Communications: An International Journal. Vol 15. No. 1, pp. 62-77 Wright, T. (2015). New development: Can 'social value' requirements on public authorities be used in procurement to increase women's participation in the UK construction industry?. Public Money \& Management, 35(2), 135-140. Young, D. (2015). Social Value Act Review. Cabinet office. 


\begin{tabular}{|l|l|}
\hline \multicolumn{1}{|c|}{ Public Sector Clients } & \multicolumn{1}{c|}{ UK Construction Contractors } \\
\hline PSC 1 - Chief Executive & CC 1 - Commercial Manager \\
\hline PSC 2 - Community Manager & CC 2 - Foundation Director \\
\hline PSC 3 - Head of Procurement & CC 3 - Head of Environmental \\
\hline PSC 4 - Procurement Manager & CC 4 - Social Value Manager \\
\hline PSC 5 - Procurement Manager & CC 5 - Stakeholder Engagement Manager \\
\hline PSC 6 - Procurement Officer & CC 6 - Sustainability Director \\
\hline PCS 7 - Social Value Manager & CC 7 - Sustainability Manager \\
\hline PCS 8 - Sustainability Officer & CC 8 - Sustainability Manager \\
\hline & CC 9 - Supply Chain Manager \\
\hline
\end{tabular}

Figure 1.0 - Interview Sample 


\begin{tabular}{|c|c|c|c|c|c|c|c|c|c|c|c|c|c|c|c|c|c|c|c|c|c|c|c|c|c|c|c|}
\hline & \multicolumn{9}{|c|}{2007} & \multicolumn{9}{|c|}{2010} & \multicolumn{9}{|c|}{2014} \\
\hline Accident* & 27 & 13 & 21 & 1 & NA & 13 & NA & 11 & NA & 1 & 5 & 33 & 1 & 19 & 15 & 0 & 4 & 7 & 0 & 2 & 9 & 5 & 32 & 24 & 3 & 15 & 11 \\
\hline Carbon* & 11 & 3 & 22 & 1 & & 9 & & 0 & & 14 & 39 & 124 & 15 & 22 & 37 & 16 & 24 & 16 & 6 & 4 & 28 & 21 & 18 & 25 & 33 & 15 & 3 \\
\hline Climate change & 13 & 0 & 10 & 0 & & 3 & & 0 & & 3 & 8 & 7 & 0 & 0 & 4 & 0 & 7 & 1 & 2 & 2 & 3 & 1 & 0 & 2 & 2 & 4 & 0 \\
\hline Code of practice* & 4 & 3 & 9 & 4 & & 4 & & 2 & & 1 & 11 & 46 & 0 & 13 & 5 & 0 & 1 & 1 & 1 & 0 & 0 & 2 & 11 & 10 & 2 & 2 & 0 \\
\hline Community & 26 & 12 & 17 & 27 & & 1 & & 4 & & 21 & 12 & 27 & 23 & 22 & 4 & 5 & 17 & 10 & 8 & 9 & 18 & 15 & 14 & 25 & 34 & 19 & 17 \\
\hline Construction & 24 & 22 & 113 & 14 & & 35 & & 11 & & 12 & 22 & 232 & 28 & 47 & 33 & 6 & 46 & 13 & 2 & 14 & 40 & 33 & 30 & 67 & 36 & 31 & 15 \\
\hline CSR & 16 & 11 & 30 & 10 & & 3 & & 2 & & 2 & 3 & 44 & 17 & 10 & 0 & 0 & 9 & 9 & 0 & 0 & 1 & 38 & 0 & 2 & 0 & 0 & 2 \\
\hline Employees* & 47 & 41 & 104 & 25 & & 23 & & 25 & & 6 & 45 & 140 & 34 & 59 & 5 & 2 & 15 & 64 & 3 & 30 & 52 & 36 & 128 & 89 & 29 & 51 & 47 \\
\hline Energy & 22 & 2 & 69 & 1 & & 23 & & 0 & & 8 & 36 & 125 & 1 & 7 & 41 & 21 & 10 & 10 & 0 & 6 & 23 & 11 & 12 & 36 & 62 & 7 & 7 \\
\hline Environment* & 53 & 53 & 84 & 27 & & 41 & & 28 & & 19 & 49 & 95 & 20 & 53 & 21 & 3 & 28 & 47 & 4 & 12 & 21 & 42 & 40 & 44 & 18 & 18 & 12 \\
\hline Ethical & 10 & 5 & 1 & 0 & & 3 & & 0 & & 1 & 18 & 4 & 3 & 6 & 12 & 0 & 0 & 7 & 5 & 0 & 0 & 3 & 7 & 50 & 2 & 0 & 1 \\
\hline Leadership & 6 & 2 & 1 & 4 & & 8 & & 5 & & 1 & 22 & 1 & 5 & 12 & 11 & 2 & 10 & 4 & 2 & 4 & 3 & 3 & 27 & 46 & 4 & 6 & 4 \\
\hline Local & 14 & 13 & 22 & 13 & & 19 & & 1 & & 5 & 23 & 34 & 6 & 10 & 5 & 2 & 14 & 5 & 6 & 33 & 30 & 20 & 12 & 19 & 24 & 8 & 7 \\
\hline $\begin{array}{l}\text { Working } \\
\text { together* }\end{array}$ & 17 & 22 & 10 & 2 & & 5 & & 3 & & 11 & 14 & 70 & 6 & 14 & 2 & 3 & 17 & 7 & 8 & 27 & 18 & 22 & 22 & 19 & 12 & 31 & 12 \\
\hline Plan & 27 & 5 & 38 & 4 & & 1 & & 6 & & 3 & 27 & 37 & 8 & 10 & 13 & 3 & 12 & 3 & 0 & 4 & 7 & 9 & 10 & 21 & 9 & 8 & 15 \\
\hline Recycling & 16 & 5 & 6 & 1 & & 6 & & 0 & & 1 & 20 & 16 & 6 & 5 & 3 & 0 & 1 & 5 & 0 & 2 & 4 & 9 & 6 & 3 & 6 & 3 & 3 \\
\hline Safety & 38 & 48 & 86 & 10 & & 26 & & 36 & & 6 & 34 & 123 & 28 & 38 & 36 & 4 & 5 & 43 & 2 & 24 & 4 & 17 & 54 & 68 & 13 & 46 & 20 \\
\hline Sustainability* & 139 & 11 & 97 & 18 & & 31 & & 3 & & 37 & 192 & 256 & 8 & 21 & 27 & 13 & 60 & 15 & 34 & 25 & 52 & 48 & 32 & 28 & 78 & 32 & 44 \\
\hline Training & 30 & 18 & 15 & 17 & & 16 & & 13 & & 6 & 17 & 52 & 14 & 25 & 6 & 3 & 10 & 11 & 1 & 14 & 16 & 17 & 29 & 21 & 21 & 25 & 24 \\
\hline Values & 24 & 4 & 2 & 5 & & 3 & & 7 & & 6 & 31 & 53 & 3 & 6 & 1 & 1 & 8 & 12 & 2 & 10 & 4 & 22 & 16 & 36 & 23 & 7 & 6 \\
\hline Waste & 20 & 8 & 23 & 3 & & 1 & & 0 & & 11 & 30 & 91 & 25 & 16 & 6 & 3 & 8 & 13 & 6 & 12 & 41 & 30 & 15 & 19 & 29 & 13 & 5 \\
\hline & 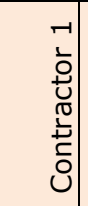 & 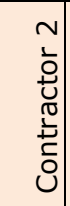 & $\begin{array}{l}m \\
m \\
\overline{0} \\
\stackrel{0}{0} \\
\mathbb{0} \\
\stackrel{0}{0} \\
0 \\
0\end{array}$ & \begin{tabular}{l|l}
+ \\
$\vdots$ \\
$\vdots$ \\
0 \\
0 \\
\\
$\vdots$ \\
0 \\
0
\end{tabular} & 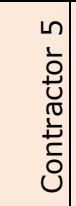 & 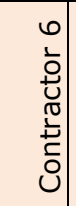 & 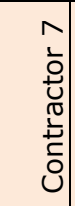 & 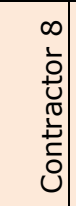 & 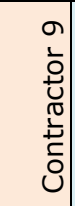 & 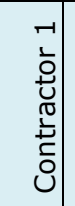 & 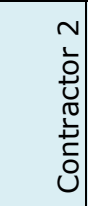 & 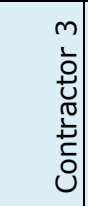 & 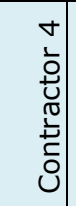 & 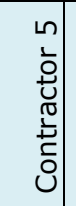 & 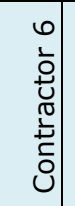 & 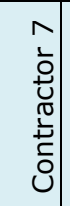 & $\begin{array}{l}\infty \\
\infty \\
\overline{0} \\
+ \\
0 \\
\mathbb{0} \\
+ \\
0 \\
0 \\
0\end{array}$ & \begin{tabular}{l|l}
$a$ \\
$\vdots$ \\
$\vdots$ \\
0 \\
$\mathbb{0}$ \\
$\vdots$ \\
$\vdots$ \\
0 \\
0
\end{tabular} & 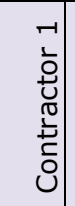 & 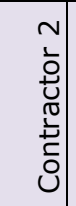 & 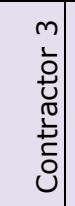 & 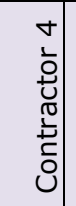 & 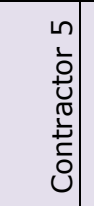 & 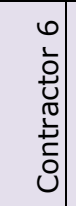 & 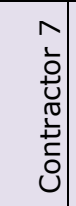 & 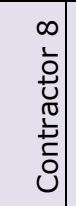 & 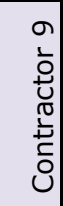 \\
\hline
\end{tabular}

* Includes associated words

(Figure 2.0 - Qualitative Content Analysis results) 